\title{
Imagem, cinema e psicologia: compondo aproximações entre arte e ciência
}

\author{
Gabriel Bueno ${ }^{\text {a* }}$ (1) \\ Andréa Vieira Zanella ${ }^{b}$ @i \\ aFaculdade Cesusc, Florianópolis, SC, Brasil \\ 'Universidade Federal de Santa Catarina, Florianópolis, SC, Brasil
}

Resumo: Imagem, cinema e psicologia - este artigo tece um diálogo entre esses três complexos e abrangentes temas para desenvolver algumas aproximações teórico-conceituais entre arte e ciência. Tendo como referência a arte cinematográfica, alguns dos recursos técnicos utilizados na composição de suas obras e conceitos oriundos dessa linguagem, o artigo procura içar pontes que partam do campo da estética para agregar reflexões referentes aos processos de subjetivação. Esta alçada tem como horizonte a filosofia da imagem e do tempo de Gilles Deleuze entrelaçada à compreensão benjaminiana da imagem como constituinte do pensamento e o tempo como um eterno agora que não cessa de se atualizar. Ambas as teorias são abordadas de forma dialógica para estabelecer cruzamentos com outros pensadores do cinema e da cultura, bem como com algumas obras fílmicas.

Palavras-chave: cinema, psicologia, imagem, Deleuze, Benjamin.

\section{Introdução}

Imagem, cinema e psicologia: eis três vastos universos que este artigo procura entrelaçar. Arte e ciência, dois campos assaz consolidados no transcorrer da história e, no entanto, regimes discursivos distintos no que se refere ao corte no real que cada um realiza (Sampaio, 2007). Este texto realizará um percurso por conceitos-imagens que abordam o cinema como forma de pensar o real e navegar pelo humano, discutindo como essas características da sétima arte podem corroborar com a produção de conhecimentos em psicologia naquilo que tange uma reflexão referente os processos de subjetivação. Ao expor alguns conceitos de Gilles Deleuze e Walter Benjamin referentes ao cinema e, na sequência, apresentar alguns dos recursos metodológicos desta linguagem artística, o texto que se segue busca suscitar uma possível aproximação entre o arcabouço técnico-conceitual da arte cinematográfica e os fenômenos concernentes à constituição do próprio pensamento e suas implicações nos processos de subjetivação.

Porém, antes de entrar em uma análise técnicoconceitual da linguagem cinematográfica, é interessante problematizar a presença do cinema na cultura moderna e contemporânea desde sua invenção, ao final do século XIX, até os dias de hoje. A partir da elaboração de uma teoria do cinema, de uma formalização dessa linguagem, do desenvolvimento de um saber teórico e filosófico sobre a arte da imagem em movimento, com seu desenvolvimento fortemente marcado pelas características políticas, tecnológicas e sociais do século XX, o cinema ocupou um lugar privilegiado na sociedade contemporânea, sendo expressão estética e,

*Endereço para correspondência: gbapsi@gmail.com dialeticamente, agente constituinte dessa mesma sociedade (Benjamin, 2008; Carrière, 2015; Hobsbawm, 1995).

Esse importante lugar simbólico na nossa cultura caracterizado pelas imagens-movimento -, fonte de entretenimento, comunicação, afecções e produção de discursividades sobre o contemporâneo, há de contribuir com algo à psicologia, e esta se enriquecerá se escutar o que essa linguagem artística tem a dizer sobre o social, sobre o sujeito e sobre o real (Carrière, 2015).

Algumas características compositivas do cinema permitem que diversos aspectos do humano e da realidade sejam explorados, pensados, pesquisados. A obra narrativa pode fazer ver histórias singulares de contextos longínquos, distante de nosso cotidiano, revelando assim realidades impensáveis devido a sua distância no tempo ou no espaço. Essa viagem não necessariamente precisa ser em territórios ou tempos distantes, pois igualmente desconhecidas podem ser dinâmicas afetivas e condições de vida comuns em nossa sociedade, porém invisíveis a muitos olhos. O cinema pode dar a ver, operar sobre os regimes de visibilidade e "dizibilidade", ao lançar sobre histórias, afetos e sujeitos o foco da câmera e a montagem narrativa para testemunhá-las ao mundo. Desenvolve assim conhecimento semelhante ao de áreas consolidadas da ciência, como antropologia, psicologia, sociedade, historiografia.

O cinema não existe somente na tela. Ele transborda das/nas experiências cotidianas. Suas histórias nos impactam no íntimo, pois sua linguagem revela, com significante grau de realismo, nossa própria vida. As imagens em movimento que nos chegam, fragmentos de acontecimentos no tempo e no espaço, sejam ficcionais ou documentais, estão carregados de elementos que interpelam o humano e que facilmente promovem projeções e identificação (Morin, 2018). 
A este "transbordar" também são direcionadas diversas perspectivas distópicas em relação à excessiva presença da imagem na sociedade contemporânea. As críticas apocalípticas $(E c o, 2006)$ referentes ao cinema e à cultura de massa atestam que tais fenômenos corroboram com a homogeneização das subjetividades, destruindo as culturas locais e a possibilidade de experiências singulares; propagam uma visão ideológica acrítica que condiciona o sujeito à passividade e a uma condição subserviente ao capital; destituem das pessoas a possibilidade de ter consciência social e histórica; promovem um tipo superficial de contemplação estética, voltada unicamente para o entretenimento e para o entorpecimento; mascaram-se de uma cultura legitimamente popular, mas são impostas de cima por indústrias que almejam aumentar seus lucros e controlar as massas. Como ironizam Adorno e Horkheimer (2014), "o cinema faz publicidade para o truste cultural maquínico no seu todo" (p. 58).

Em contrapartida, a busca por uma imagem que escape ao movimento da sociedade do espetáculo, que encontre algo de sensível e reflita algo de uma humanidade escamoteada nos tempos de enorme profusão de informações, parece ser a busca de alguns diretores do cinema (Wenders, 1985), mas que veem o status da imagem na contemporaneidade com pessimismo.

A aliança entre espetáculo, entretenimento e mercadoria, denunciada por Guy Debord (1997), foi consolidada ao longo do século XX. As linguagens artísticas foram cooptadas pelo capital para anestesiar $\mathrm{o}$ pensamento e condicionar as populações a uma forma de consumo homogeneizada e acrítica: entretenimento como ópio do povo (Comolli, 2010). No entanto cabe a cada linguagem fazer resistência diante desse uso mercadológico, viabilizando que a arte e seu espectador venham a tecer formulações independentes e críticas referentes aos sentidos, às afecções e reflexões possíveis que a obra pode suscitar. Assim, o cinema precisa resistir às intenções totalizantes do mercado, pois "lutar contra sua dominação é travar um combate vital para salvar e possuir algo da dimensão humana" (Comolli, 2010, p. 12, tradução nossa).

Não ignorando esse amplo espectro no qual qualquer reflexão sobre o cinema deparará, inserido nas problemáticas culturais que giram em torno dessa temática, o tópico a seguir discorre sobre a imagem cinematográfica em Gilles Deleuze e em Walter Benjamin, e traça um paralelo conceitual entre a imagem no cinema e a imagem na psicologia, apontando como a linguagem cinematográfica e o trabalho teórico desenvolvido em torno do conceito de imagem podem corroborar com estudos oriundos da psicologia, na busca por elaborar algo referente a uma teoria sobre os processos de subjetivação.

\section{O conceito da imagem em Deleuze e Benjamin}

Partindo da problematização referente ao lugar que o cinema ocupa na cultura moderna e contemporânea, podemos supor que algo do seu léxico técnico-conceitual pode corroborar com as produções de conhecimento referentes ao social, à natureza e ao humano. Assim, buscando utilizar a teoria do cinema para compreender alguns fenômenos referentes aos processos de subjetivação, propomos explorar o conceito de imagem em Deleuze e Benjamin para, na sequência, vincular a imagem ao tema da constituição da subjetividade.

Por mais comum e usual que seja a utilização da palavra "imagem" em nosso cotidiano, sua abrangência conceitual se mostra um tanto complexa ou mesmo vaga, seja na arte, na ciência ou na filosofia. Ela pode ser abordada, a princípio, por questões relativas à percepção e sua visualidade, via pela qual a imagem se torna um objeto de relação. Por conseguinte, o estímulo visual não é suficiente para tornar a imagem "visível". É preciso que o sujeito a tome como participante do seu imaginário e a coloque como rede de sentidos e significados para que possa estabelecer com ela alguma relação. Podemos pensá-la na relação com o dispositivo que a porta e a projeta no mundo, determinando-lhe um contexto e sua presença na dialética social. Ademais, pode-se questioná-la em sua ontologia, em sua relação com o tempo e o espaço, seu caráter representativo/constitutivo da realidade, seu lugar nas estratificações do real.

Deleuze discorre sobre a arte cinematográfica a partir do conceito de imagem-movimento e seus desdobramentos. O principal enfoque dado pelo autor à linguagem do cinema é a dimensão do plano e as possíveis camadas de apreensão do real que um plano pode compor. A imagem-movimento é propriamente o plano cinematográfico, a modulação e composição do tempo que contém um acontecimento; nas palavras do autor, a imagem-movimento é "o corte móvel de uma duração" (Deleuze, 2018, p. 44).

A imagem captada pela câmera, a composição do plano e os elementos nele contido - as paisagens humanas, o semblante dos objetos, a dinâmica dos cenários, o humor dos movimentos - constituem um conjunto infinito de imagens, situadas num plano de imanência, que narraram, nas suas expressividades, a vida, os afetos, as histórias, a materialidade que flui, que se movimenta, que escorre no decorrer do tempo (Deleuze, 2018). $\mathrm{O}$ autor distingue três variedades de imagens-movimento possíveis, segundo as qualidades imagéticas dos planos: imagem-percepção, imagem-ação e imagem-afecção, que correspondem, respectivamente, a processos perceptivos, narrativos e expressivos.

A imagem-percepção apresenta o registro do cineolho', da câmera, do que passa no seu enquadramento. Para além de todas as experiências de cunho narrativo ou afetivo que o plano procure apresentar, existe uma

\footnotetext{
1 A expressão "cine-olho" foi difundida por Dziga Vertov em seu ensaio "Nascimento do Cine-Olho", em 1924. Sob influência do futurismo, Vertov vê na máquina-câmera potencialidades para ir ao encontro com a verdade, com o real, superando as limitações psicológicas humanas que a impedem o sujeito de realizar este feito (Vertov, 2018).
} 
imagem sendo registrada por essa outra consciência que "reflete seu conteúdo numa consciência-câmera que se tornou autônoma" (Deleuze, 2018, p. 124). A câmera registra um ponto de vista como se dos objetos ou no espaço eclodissem olhos que dão a ver um acontecimento, em que a imagem-percepção dá à contemplação uma janela que se abre ao mundo. É uma imagem que fornece elementos para a imaginação se situar e contextualizar por onde paira.

A "consciência autônoma" de que Deleuze nos fala não se trata da imposição de uma percepção totalizante e objetiva, mas seu contrário: a possibilidade de uma percepção singular-subjetiva que referencia a cena a um sujeito, sendo este capturado segundo suas próprias inclinações. Por substituição ou eliminação perceptiva referente ao que está dado na captura da objetiva $^{2}$, a imagem-percepção permite singularizar a apreensão do vivido registrado numa imagemmovimento; a imagem-percepção se supõe polissêmica, múltiplos sentidos num mesmo registro.

$\mathrm{Na}$ imagem-ação reside a potência narrativa das imagens, a possibilidade de atualizar em si "meios e comportamentos", contar histórias, causos, acontecimentos. A imagem-ação apresenta situações que se modificam a partir da ação, do movimento e da existência devido a sua capacidade de intervir e modular o real, de fazer advir um novo na corrente da imagemmovimento, do corte móvel, do plano.

É característica da imagem-ação favorecer o entendimento da história e constituir relações entre as situações, os sujeitos, os espaços nos quais o filme transcorre. Nela se atualizam sentidos mais consolidados do que nas outras duas variedades de imagem-movimento (perceptiva e afetiva). A imagemação agrega nome aos personagens, expõe a relação existente entre eles, explora as situações nas quais estão envolvidos, descreve contextos. É a potência de modificar as situações, transformando-as em novas realidades; é a exposição dos acontecimentos.

A imagem-afecção se refere à potência expressiva que o cinema pode compor. Espaço privilegiado para a composição das experiências afetivas possíveis. Deleuze identifica a imagem-afecção como o primeiroplano, o rosto humano, imagem que oferece uma apreensão sensível do filme. Momento de suspensão da narrativa, o destaque proporcionado pela imagemafecção (pelo primeiro-plano) não procura agregar necessariamente elementos a uma história contada, mas suscitar afetos, provocar reações, acordar os monstros, desencadear identificações, desejos e fetiches. Não se supõe como objeto narrativo, mas como experiência sublime, no sentido que ocasiona uma ruptura com o encadeamento lógico da história para advir um encontro com o afetivo.

O rosto, na lógica da imagem-afecção, pode ser encarnado em objetos, lugares, animais, plantas, todo o não-humano. $\mathrm{O}$ rosto expressivo e potência de afeto é a presença de uma anima, de um algo que suscite a indagação sobre o que se passa com esse Ser, o que sente, o que pensa. A experiência proporcionada pela imagem-afecção é mesmo complexa de se exprimir em palavras, visto que é da ordem do sentir, e não do logos racional. Como observa Deleuze (2018), a imagemafecção é "difícil de definir, pois é mais sentida do que concebida - ela diz respeito ao novo na experiência, o fresco, o fugaz e, no entanto, o eterno" (p. 156).
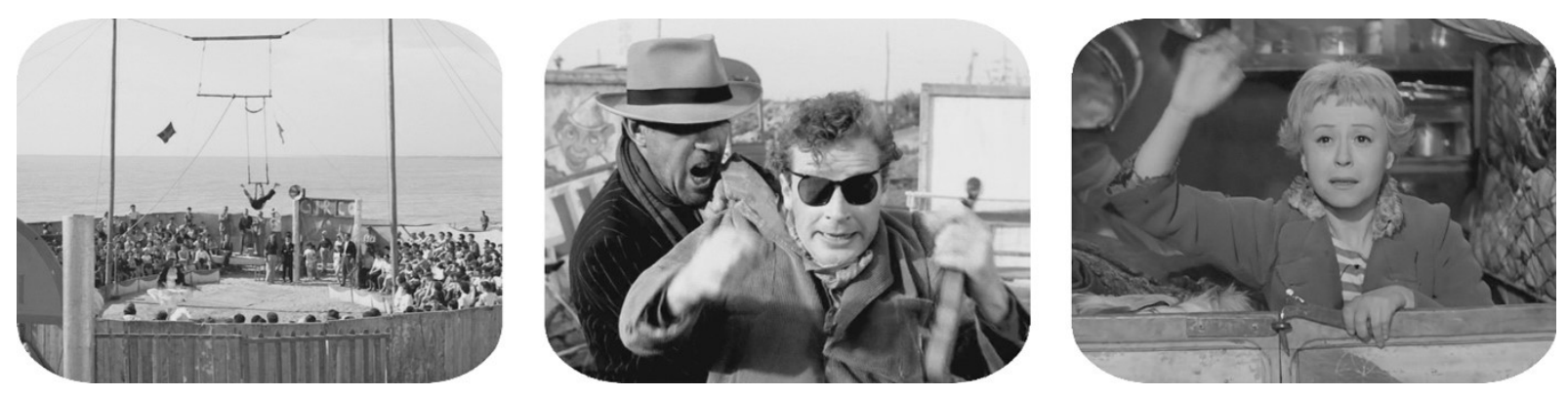

Figura 1. Da esquerda para a direita: imagem-percepção, imagem-ação e imagem-afecção na obra La strada, de Frederico Fellini, 1954

As obras do cinema são sempre uma composição das três variedades de imagem-movimento: as imagenspercepção são características dos planos de enquadramentos mais abertos, que apresentem um conjunto de informações dispostas visualmente, sem eleger destaques, elementos

2 Na câmera fotográfica ou de filmagem, a objetiva (conhecida popularmente como "lente") é por onde a luz entra no dispositivo, é seu olho. Não por acaso é chamada de objetiva, visto que a ideia de que seu registro é fidedigno a uma realidade concreta. dispostos em uma hierarquia horizontal; as imagensação, apresentadas geralmente num plano médio, em que a história se desdobra numa concatenação lógica e as relações entre os elementos do filme são desenvolvidas; e as imagens-afecções, primeiro-planos, em que a narrativa é colocada num tempo paralelo e em que advêm as qualidades sensíveis. A relação entre as imagens-movimento se dará pela montagem, em que uma das variedades tende a prevalecer sobre as outras 
duas, de acordo com as afinidades estéticas do artista (no caso do cinema, o diretor).

Em Deleuze, as imagens correspondem a encontros e composições do real em diferentes camadas. As imagens do cinema não são diferentes das experiências do sujeito na sua existência, dos graus de encontro deste com a vida. $\mathrm{Na}$ verdade, linguagem cinematográfica pode ser mesmo uma analogia das experiências subjetivas humanas. As três variedades de imagem-movimento compõem uma quarta: a imagem-pensamento, resultante de uma síntese em movimento das três formas de apreensão do real. Seria essa, justamente, nossa forma de relação e constituição de um entendimento do mundo, um processo de subjetivação mediado pela recepção e (dis)junção da percepção de um contexto, da ação narrativa e das afecções advindas desse encontro.

Estabelecendo paralelos com a teoria da imagem de Deleuze, o conceito de imagem em Benjamin (2012a, 2012b, 2012c) aparece, assim como em Deleuze, intimamente ligado ao subjetivo, podendo ser elencado como conceito valioso para se pensar os processos de subjetivação. Em seus ensaios sobre o espaço urbano ("Rua de mão única", "Infância em Berlin por Volta de 1900", "Imagens do pensamento", Passagens), o autor resgata de forma literária as imagens que povoam sua memória em relação a esses momentos vividos. Inspirado na prosa proustiana, na forma que o autor francês narrava suas experiências recorrendo a traços mnêmicos, Benjamin procurou desenvolver uma narrativa que recorre às imagens do pensamento referentes a um passado que não deixa de se atualizar dialeticamente mediado pelo espírito do presente.

Para Benjamin, o pensamento é constituído de imagens, como no processo da arte da gravura, em que um molde deixa vestígios sobre uma superfície a ser gravada - ou como a fotografia, na qual a luz captada pela lente deixa um registro sobre um anteparo fotossensível. De forma análoga, fragmentos do vivido, acontecimentos, podem se fixar sobre o sujeito, deixam-lhe marcas, que são resgatadas como imagens de uma experiência. $\mathrm{O}$ autor se lança num paradigma epistemológico de compreensão do sujeito em que o pensamento está mediado por experiências estéticas e composto justamente desses registros imago-afetivos. A imagem em Benjamin não apenas ilustra o mundo, "ela é parte de um processo de construção de linhas de pensamento, . . . ele não só pensa por meio de imagens, ele também pensa com imagens." (Pernisa \& Landim, 2008, p. 29). A imagem em Benjamin ganha status ontológico, visto que ela compõe o sujeito e este se refere ao mundo mediado por impressões imagéticas.

Assim como as obras de arte, que, com o efeito do tempo, passam por transmutações - quando suas cores tornam-se pálidas, o papel desbota, as superfícies descascam, o bronze oxida, a madeira trabalha e novos discursos e novas percepções são lançadas sobre elas, recontextualizando seu significado na cultura-, as imagens do pensamento também estão sendo constantemente atualizadas. As imagens do pensamento não são ícones no sentido peirceano, no entanto associam-se mais à lógica dos indices $^{3}$ : rastros de uma passagem, de um vivido que nunca cessa de ser reinterpretado. Assim, a imagem benjaminiana é uma imagem-dialética, destituída de uma cronologia linear, ela é "aquilo em que o ocorrido encontra o agora" (Benjamin, 2009, p. 505), estabelecendo uma constelação de fragmentos imagéticos da história que não param de se atualizar no presente, segundo uma significação sempre momentânea, provisória e histórica.

Para Benjamin, a imagem constitui o pensamento assim como participa da própria condição da linguagem:

se a escrita quiser garantir o seu caráter sagrado, ... ela terá de se organizar em complexos de sinais, em sistemas de hieróglifos. . . Do ponto de vista externo e estilístico - no caráter exuberante da composição tipográfica e excessivo da metáfora a escrita tende para a imagem (Benjamin, 2016, p. 187).

Talvez seja na linguagem das artes visuais que o sistema de ideogramas se manifesta com mais evidência na cultura ocidental, em que uma ideia é elaborada e transmitida por via de produções imagéticas. Para o autor, o processo de montagem cinematográfica é análogo à constituição do próprio pensamento, onde imagens aglutinadas em determinada lógica constituem ideias referentes ao vivido e interpretações da realidade.

No cinema, as imagens registradas pela câmera evidenciam um visível inalcançável ao olhar, devido a seus recursos técnicos e estéticos, como a câmera lenta, o close, o foco, o flash back, o corte e a justaposição da imagem. A imagem pode trazer à tona aquilo que passa despercebido ou invisibilizado nas experiências cotidianas (Benjamin, 2008). O trabalho da câmera pode ser de escavação e revelação de aspectos humanos, antropológicos, sociais, estéticos e políticos ao promover essa pesquisa imagética sobre o real.

A produção e relação com imagens é o constituinte do sujeito em Benjamin. Seus pensamentos, sua história e sua posição axiológica no social é mediado pelo conteúdo imagético que compõe a rede de significações, afecções, sua narrativa sobre suas experiências e sobre a vida. E o caminho possível para conhecer esse sujeito é por via dessas mesmas imagens. Para o autor, o cinema é uma linguagem estética privilegiada para ir ao encontro das imagens fundantes do humano. Dado a esta posição favorecida que o cinema ocupa na cultura, Benjamin (2008), de forma messiânica, como é seu estilo de costume, atesta que "fazer do gigantesco aparelho técnico

3 Na teoria de Charles Peirce, um ícone se refere a um elemento de forma direta, sem ambiguidades ou deformações. Um simbolo faz referência a algo por via de convenções social, mas sua "aparência" não é semelhante àquilo que representa. E um índice é reconhecido por similaridade com o objeto que representa, como um ícone, porém essa representação é tomada como um vestígio, uma marca deixada pelo objeto representado, sendo esta sua representação indireta. 
do nosso tempo o objeto das inervações humanas é essa a tarefa histórica cuja realização dá ao cinema o seu verdadeiro sentido" (p. 174).

Portanto, respeitando as diferenças epistemológicas existente entre os dois autores analisados, que partem de matrizes distintas do pensamento filosófico, compreendemos aqui que a imagem serve a ambos para elaborar uma teoria da constituição do pensamento. Tanto Deleuze filósofo que resgata em sua teoria as reflexões espinozistas, nietzschianas e bergsonianas - quanto Benjamin - autor oriundo da teoria crítica e pensador do materialismo dialético - sugerem o conceito de imagem como componente participante dos processos que nos subjetivam. A imagem, como elaborada nas duas perspectivas, pode nos auxiliar a compreender uma teoria da constituição do sujeito a partir de um paralelo entre cinema e pensamento como dois processos que, respeitada as suas diferentes ontologias, se constituem em processos análogos.

\section{Cinema e sujeito como constituídos de imagens}

Devido aos aspectos técnicos e estéticos do cinema, como a imagem de uma realidade em mudança, o movimento do enquadramento revelando uma consciênciacâmera, o som (sons ambiente, músicas, diálogos), a elaboração de narrativas que contam de experiências humanas, os personagens e seus traços subjetivos essa linguagem favorece processos de identificação e projeção que estabelecemos com a obra que nos interpela.

Porém não é somente na relação que o expectador estabelece com a obra que cinema e psicologia formam um profícuo diálogo. Por meio de analogias ou realizando "empréstimos" de conceitos oriundos da arte cinematográfica, alguns conceitos e singularidades da linguagem que sustenta o cinema como variedade artística podem ajudar a compreender os movimentos e vicissitudes do processo de subjetivação, tema caro às abordagens da psicologia que buscam desenvolver conhecimento sobre os processos constitutivos do sujeito, como também agregar novas estratégias metodológicas às pesquisas em psicologia.

Conceitos próprios da linguagem cinematográfica, como campo, enquadramento, plano, decupagem, montagem, tempo, imagem-movimento, e as inúmeras nuances e estratificações que cada conceito comporta, podem agregar potência conceitual na pesquisa e na elaboração de uma episteme que tenha como intuito a compreensão dos processos de subjetivação. Segundo Aumont (2012), "a linguagem cinematográfica é mais ou menos compreensível como manifestação de uma linguagem interior, que nada mais é do que outro nome do próprio pensamento" (p. 95). O cinema é, assim, uma linguagem que tem estrutura similar aos processos de subjetivação, propiciando diversas aproximações conceituais e epistemológicas entre cinema e psicologia.

Aqui, o sujeito deve ser entendido em sua processualidade, em constante movimento de vir-a-ser.
A afirmação individualizante de um "eu", de um "ego" ou de um "cogito" é apenas parte de um todo maior, resultante de processos históricos, de uma impressão deixada pelo contexto político-social, de uma combinação dos agenciamentos que se incidem sobre um corpo, donde o sujeito emerge como resultante provisório desses efeitos cambiantes (Guattari \& Rolnik, 1996).

Cenas após cena, plano após plano, o filme vai tomando forma. Seu todo está sempre por se dar, pois a próxima imagem-movimento pode redefinir toda sua estrutura narrativa. Mesmo concluído, mesmo depois de anos terem se passado desde seu lançamento, o filme ainda está em processo de mutação, pois aqueles que são interpelados pelas imagens recriaram novas interpretações narrativas e traçarão nossas afecções possíveis nas imagens gravadas. Processo de subjetivação é a montagem de um plano após o outro, projeto fílmico que nunca para de ser rodado, que não abandona o set de produção; processo em aberto, agenciado pelo coletivo e tornado presença numa síntese momentânea entendida como sujeito e em sua mesa de edição.

Conceitos como imagem-mental (Aumont, 2003, 2012; Deleuze, 2013, 2018; Guido \& EstevinhoGuido, 2012) ou imagens do pensamento (Benjamin, 2008, 2012a; Pernisa \& Landim 2008) situam um campo no qual a imagem encontra o sujeito para compor seu imaginário. São imagens que estabelecem relações entre percepções, ações, afecções, tecendo uma síntese provisória, sentidos em devir no espaço e no tempo. As imagens que integram um filme (segundo um campo e seu enquadramento, os planos e suas decupagens, os objetos cênicos, os movimentos e suas durações) são as mesmas unidades que compõem nossos imaginários, em que as relações estabelecidas entre elas (a montagem) contam nossas histórias - imagens do pensamento nas quais nossas biografias tomam forma e são projetadas.

Segundo Aumont (2012), as imagens que se inscrevem no imaginário são de natureza intermediária entre o verbal e o icônico, não se identificando com um tipo de registro fotográfico subjetivo da realidade, tampouco com a ilustração de uma linguagem verbal internalizada. O imaginário é de domínio criativo e singularizante na mediação do sujeito com a realidade, e tal instância subjetiva está diretamente ligada ao conceito de imagem explorada no cinema. As imagens do cinema e do registro imaginário não permanecem atreladas à presença do vivido registrado, seja pela câmera ou pelo sujeito, desvencilhando-se de uma concepção representativa da imagem, imagem como mimésis do real. Arte e sujeito têm autonomia criativa para constituírem diegeses singulares, isto é, elaborar de forma singular as suas narrativas em relação às experiências vividas e fabular a própria história.

\section{Campo e enquadramento}

O conceito de campo no cinema se refere a um espaço imagético representado em determinado plano (fragmento de duração) e definido por um enquadramento 
específico (recorte do campo visual). São as "pinturas da realidade" registradas pela câmera, apreensão de um visível que propõe a formulação de um imaginário sobre a imagem captada. Onde o enquadramento corresponde um corte da realidade realizado pelo dispositivo técnico (a câmera), o campo corresponde às potências da imagem em sugerir essa realidade, em alimentar um imaginário sobre o que se visualiza (Aumont, 2012).

A composição do campo - se seu enquadramento é fechado ou aberto, se é saturado ou rarefeito de informações, se realiza um close ou uma panorâmica, os cenários, personagens e objetos que enquadra, a qualidade perceptiva, narrativa e expressiva dos elementos apresentados - agrega elementos qualitativos para compor a imagem-percepção, a imagem-ação, a imagem-afecção. A forma como a apreensão da realidade é filmada e a composição imagética resultante corroboram com a elaboração estética de sensibilidades distintas. O campo pode definir uma perspectiva sobre o vivido e engendrar afecções referentes a ele. Ele tem uma potência de enunciação. A forma como o vivido é captado, seja pela câmera na produção cinematográfica ou por um sujeito na experiência cotidiana, poderá determinar as qualidades subjetivas e as relações sensíveis estabelecidas com esse vivido, constituindo uma rede de sentidos.

A visualidade que constitui um campo se definirá não pelos aspectos objetivos que compõem a imagem, mas pelas relações perceptivas, afetivas e narrativas que pode sugerir. Mudanças nos enquadramentos podem corresponder a outros pontos de vista sobre a realidade. Um jogo de tornar visível e invisível, de fazer ver o que antes se encontrava fora de campo. $\mathrm{O}$ cinema realiza um jogo de enquadramentos, a partir da montagem, provocando movimentos nas afecções e reflexões suscitadas pela dinâmica das imagens, "reenquadramento como funções do pensamento" (Deleuze, 2013, p. 36).

O jogo dos enquadramentos é uma operação de visibilidades, em que algo se destaca e vem à luz, vem tomar participação no social, enquanto outras tantas permanecem como se nunca tivessem existido. A arte vem intervir na distribuição geral das formas de visibilidade, acarretando em produções de discursos e de sentidos (Rancière, 2005). Essa potência da arte - em definir aquilo que é partilhado e tornado sensível à razão, ao outro, ao coletivo - intercede na dinâmica do político assim como do subjetivo. Ela fornece elementos estéticos e axiológicos para o movimento incessante e constituinte de uma coletividade, assim como agrega novos ou reafirma velhos enunciados aos processos de subjetivação.

Para cada enquadramento resta um todo maior representado pelo fora de campo. Por essa janela que se observa o mundo, supõe-se que há toda uma realidade circundante que permanece não visível. Portanto todo campo não passa de um fragmento organizado sob um ponto de vista específico. Logo é possível pensar o contexto do qual esse campo foi extraído e as condições dadas para que o enquadramento fosse um, e não outro.
O enquadramento cinematográfico define, assim, uma imagem-movimento constituída pelo dispositivo técnico e pelas afecções que o quadro procura engendrar, assim como o sujeito é constituído de imagens-pensamento rabiscadas nas suas relações histórico-culturais. Assim, se o cinema é um jogo de enquadramentos, podemos pensar que viver também o é.

Outra faculdade do campo é a sua potência investigativa. $\mathrm{O}$ olhar debruçado sobre o objeto, sobre a cidade, sobre o humano faz ver o elemento por vezes invisível ao transeunte despercebido, favorecendo que o olhar possa reconhecer algo antes não concebido. As variações de enquadramentos podem tornar visíveis tanto grandes espaços e aglomerados de elementos quanto fragmentos singulares e insólitos.

Um dos enquadramentos mais característicos do cinema, compreendido como a alma da arte cinematográfica (Aumont, 2012), é o close. O foco fechado do close mergulha sob um pequeno aspecto da realidade para acessar o inconsciente óptico, tal como afirma Benjamin (2008), não captado pelos olhares inadvertidos do dia a dia ${ }^{4}$. O close comporta a potência de aprofundar os olhares sobre os recônditos da vida, proporcionando "uma proximidade psíquica e a uma 'intimidade' .. . materializa quase que literalmente a metáfora do tato visual" (Aumont, 2012, p. 146). Sua potência investigativa vai além do encontro com uma realidade objetiva e material para tornar passível de reflexão também aspectos sensíveis e afetivos. Se a imagem-afecção é definida por Deleuze principalmente pelo primeiro-plano e pela função rosto, o close surge com técnica privilegiada para causar a impressão desejada pela imagem-afecção, que consiste na elaboração e investigação estética das qualidades sensíveis.

\section{Plano e decupagem}

A imagem-movimento é o plano cinematográfico que consiste num corte móvel, um segmento de tempo selecionado por meio da decupagem. É no plano que toda exposição, narrativa, ação ou afecção se desenrola, a partir da qualidade das imagens que o compõe. Cada plano é pensando com o intuito de dar visibilidade a uma imagem em devir que, no todo, constitui a obra. A decupagem é o processo técnico que corresponde à seleção dos planos e à determinação de seu início e fim, definindo a duração do plano a partir do corte.

Os planos são as unidades que erigem um filme após serem organizadas a partir da montagem, em que o

4 "A natureza que fala a câmera não é a mesma que fala ao olhar; é outra, especialmente porque substitui a um espaço trabalhado conscientemente pelo homem, um espaço que ele percorre inconscientemente. Percebemos, em geral, o movimento de um homem que caminha, ainda que em grandes traços, mas nada percebemos de sua atitude na exata fração de segundo em que ele dá um passo. A fotografia nos mostra essa atitude, através dos seus recursos auxiliares: câmera lenta, ampliação. Só a fotografia revela esse inconsciente ótico, como só a psicanálise revela o inconsciente pulsional” (Benjamin, 2008, p. 94). 
sentido de cada plano é concebido na sua relação com os demais planos que o antecederam e o sucederão. A lógica constituída na montagem dos planos fica atrelada à cadeia de imagem-movimento, não sendo expressão de uma linearidade serial, mas um todo que toma forma na relação (Merleau-Ponty, 2018).

Os blocos de espaço-tempo apresentados pelo plano não param de se desequilibrar e reequilibrar, visto que o fragmento fílmico não corresponde a uma realidade estática, pois está compelido a mudar constantemente, e a relação entre os planos coloca a cadeia em movimento espiral, com idas e vindas na constituição do sentido estabelecido entre eles.

Segundo Deleuze (2018), o plano é um trecho de duração que foi segmentado artificialmente da sua cadência, extraído de um todo temporal e procura representar o próprio tempo por meio das mudanças que transcorrem em seu interior. O tempo, inapreensível por si só, tem sua presença expressa por meio da imagem que muda. A mudança é a evidência de uma passagem, de uma perspectiva temporal. Por isso a imagem ocupa lugar importante na filosofia do autor, visto ser a imagem em transformação evidência, e o acesso, possível à dimensão do tempo.

A estrutura de um plano, que decorre da exposição de um vivido, uma experiência registrada sob determinado enquadramento, um corte do tempo que se fixa como cena, constitui unidades narrativas que também compõem o mosaico narrativo da experiência do sujeito. O plano é um registro imagético que nos remete a uma cena, traz à tona pessoas, situações, afetos que compartilharam o mesmo espaço, o mesmo acontecimento. $\mathrm{O}$ conceito de plano se assemelha às imagens em movimento que inscrevem nossas memórias e que contam os acontecimentos que tecem nossa história. A imagem em movimento que caracteriza o plano no processo de subjetivação são os fragmentos imagéticos que nos remetem ao passado, ao presente e ao futuro, constituindo uma concepção de existência, de sujeito, mediado pelo encontro com um outro, pelas identificações traçadas, pelos afetos e emoções que nos marcaram, pelos projetos e expectativas que nos remetem a um futuro, pelos desejos que nos impulsionam às ações, escolhas e afecções no cotidiano.

\section{Holy moment}

O cinema tem potência de revelação. Ele registra as situações que se encanam sob o enquadramento da câmera, oportunizando a transcendência do corte móvel em relação ao tempo e espaço. Ele mostra lugar, pessoas, situações, a vida acontecendo, os afetos exprimidos seus recursos dão a ver o vivido, em que situações distantes podem ser visualizadas e acompanhadas num contexto deveras distinto do seu momento de criação. Ele aponta, com seus recursos de câmera, como o close, o primeiro plano, o enquadramento, o foco, para elementos a serem destacados, com intuito de expor uma relevância, um significado, um inusitado, uma importância. Ele escava acontecimentos nos quais o singular pode ser encontrado em meio à profusão de situações e estímulos. Ele revela um real, um possível contido num fragmento de tempo acolhido pela imagem.

Os verbos apresentados, associados às potências do cinema que derivam de propriedades óticas e temporais, tendem a concentrar seus efeitos na capacidade de tornar visível e compartilhável um acontecimento. $\mathrm{O}$ cinema não descreve, como na literatura, os acontecimentos. Não tende a haver explanações verbalizadas do que procura comunicar (Merleau-Ponty, 2018). No entanto o cinema nos dá a ver, nos oferece certa concretude do vivido a partir das imagens-movimento - a fantasia se materializa, o fictício se revela como existente e, com alto grau de realismo, se apresenta sob nossos olhos.

No filme Waking life (2001), o cineasta Caveh Zahedi utiliza a expressão holy moment para designar essa potência do cinema em destacar um fragmento do real e causar uma experiência catártica a partir dessa revelação. Zahedi discorre que cada imagem do cinema é uma face da vida que extrapola o momento do acontecido para se tornar "sagrada", no sentido que adquire uma qualidade que transcende sua condição física de ser vivente num tempo determinado e num espaço específico. Cada quadro e cada plano diz sobre aquele específico momento, e este se torna sagrado por ser uma face da vida que agora adquire outro status ontológico.

Indo ao encontro dos holy moments de Zahedi, Deleuze (2013) vê na constituição das imagens do cinema uma forte vocação a causar choques e perturbações, devido ao fato de que a imagem na linguagem cinematográfica é:

algo poderoso demais, ou injusto demais, mas às vezes também belo demais, e que portanto excede nossos capacidades sensório-motoras. Stromboli: uma beleza grande demais para nós, como uma dor demasiado forte. Pode ser uma situação limite, a erupção de um vulcão, mas também o mais banal, uma mera fábrica, um terreno baldio (Deleuze, 2013, p. 29).

$\mathrm{O}$ efeito acarretado pela imagem-movimento pode convocar a uma disruptura do ego, em que a experiência suscitada pela obra já não pode ser abarcada pelo pensamento lógico-racional, passando a predominar mais a ordem do sentir do que a do pensar. O imaginário leva um choque na sua insuficiência intelectual, e dessa impossibilidade advém o sublime, o sagrado (Deleuze, 2013). A experiência do sublime não remete somente à sedação que a presença do belo na arte causa: o encontro com o harmônico, lugar de prazer, tranquilidade, leveza e contemplação, correspondendo às expectativas do sujeito e da cultura. O sublime vai também ao encontro da experiência do choque: da desorganização egoica, do horror, do desconforto, do choro engasgado ou 
das lágrimas que transbordam, do riso histérico, da raiva e do torpor (Fortes, 2015).

Assim, a arte pode propiciar a abertura para uma experiência sensível fazendo advir algo do humano que a ciência, a razão e as palavras por vezes não alcançam. As imagens do cinema corroboram com a pesquisa e com o conhecimento a respeito desse humano na busca, no compartilhamento e na vivência de sensibilidades outras. Para realizar tal feito, o método, aqui, é uma prática do sentir, do experienciar; é ir ao encontro de algo, sob a égide da ficção que a razão ainda não pode formular e que o método científico tradicional não comporta nos seus critérios de cientificidade.

\section{Conclusão}

Para concluir, distanciamo-nos agora um pouco da discussão anterior para percorrer por uma obra fílmica, a fim de fazer advir um conhecimento que pode eclodir a partir da relação com a arte.

As imagens de La strada foram filmadas na década de 1950, numa Itália pós-guerra derrotada. Uma sociedade que convivia com a pobreza e com o desafio da reconstrução. Os personagens do filme, Gelsomina e Zampanò, são dois artistas mambembes unidos pelas circunstâncias e pela necessidade. A primeira, uma dentre os muitos filhos de uma mãe solteira abandonada pelo marido, inocente e sentimental, crente na bondade e demandante do amor do homem que a levara como sua esposa pelo valor de algumas liras. Ele, um larápio grosseiro e promíscuo, egoísta em suas relações, porém um náufrago em sua solidão. Mesmo vivendo uma relação amorosa mediada pela agressividade e pelo sofrimento, voltavam sempre a desejar estarem juntos, sem saber bem por que. Ambos partem a perambular pelo interior do país, apresentando, por onde passam, encenações cômicas e truques medíocres para garantir algum sustento e se embriagar.

$\mathrm{O}$ road movie de Fellini nos remete, mais de meio século depois, a um contexto de incertezas quanto ao futuro em um país desolado pela crise econômica e com uma infraestrutura em ruínas. Expõe a penúria de uma população que junta os cacos deixados pela guerra para tentar sobreviver, numa marcha mais desacreditada do que balizada pela esperança no futuro. O filme, além de ser a história de dois personagens fictícios, é um relato das condições de existência e dos afetos que atravessavam uma sociedade ferida. Narrar o sofrimento e as mazelas deixadas pelo fascismo foi o que deu identidade ao neorrealismo italiano, movimento estético/cinematográfico no qual
Fellini é identificado como pertencente na história do cinema e que buscou - como forma de resistência política por meio da arte - denunciar a realidade social e econômica que a Itália e o mundo viviam após os traumas da Segunda Guerra Mundial.

Já não tão fictícios são esses personagens se os interpretarmos como uma narração de experiências vividas por parte da população mundial que, na década de 1950, teve que conviver com as sequelas da Segunda Grande Guerra, e como também vivem, ainda hoje, em muitas sociedades, povos que se esgueiram sob destroços e que reinventam modos de existir em sociedades arruinadas por crises econômicas, guerras civis, espólio estrangeiro, pelo abandono de suas populações à própria sorte. La strada nos conecta com um social e um sensível, facetas da experiência humana de complexa descrição por meio de palavras. A solidão, a tristeza, o abandono, a pobreza que o filme narra não estão restritos ao plano da fantasia ou de uma inexistente ficção. Pelo contrário, a obra traz à tona um real de um modo tão intenso que sensibiliza o expectador para sentir sua presença, a vida na sua dureza.

Essa empreitada filosófico-cinematográfica que procura dar contorno a um real é trilhada por intermédio das composições arranjadas entre imagenspercepção, imagens-ação e imagens-afecção. Cada uma dessas variedades da imagem-movimento favorece que uma parte do real possa ser vista, pensada, apreciada. São constitutivas de um saber sobre o mundo, sobre o vivido - um saber composto de fragmentos esparsos, de sensações afetivas e fisiológicas, de relações sensíveis. A arte se lança na produção de conhecimento numa trama complexa, pois "a imagem nunca é de uma realidade simples. As imagens do cinema são, antes de mais nada, operações, relações entre o dizível e o visível, maneiras de jogar com o antes e o depois, a causa e o efeito" (Rancière, 2012, p. 14).

O cinema, os conceitos que o constituem e sua linguagem falam, assim, do próprio sujeito, são expressão do humano. Por mais irreal que uma história possa parecer, lá reside uma criação humana, decorrente de desejos, projeções, fantasias, anseios, sublimações. É trabalho de um autor ou de um coletivo (visto que no cinema as obras são produções que envolvem grande número de pessoas) e será objeto de identificação, de afecção, de revelação para muitos outros. Há, naquelas histórias, um suposto saber sobre a vida e sobre nossos anseios e sentimentos mais íntimos e bem guardados. A arte em geral pode dizer muito sobre o sujeito, por vezes mais que os tratados científicos - e nós sabemos disso, pois somos tocados por ela.

\section{Image, cinema and psychology: approaches between art and science}

Abstract: Image, cinema and psychology - this article weaves a dialogue between these three extensive and complex topics to develop theoretical-conceptual approaches between art and science. From the cinematic art, some of its technical 
resources and concepts developed by this language, the article seeks to provide a bridge between the field of aesthetics and reflections on the process of subjectivation. The paper finds grounds on Deleuze's philosophy of image and time and Benjamin's understanding of the image as a substance shapes thought and time as an eternal instant that never ceases to update itself. Both theories are approached in a dialogical way to establish intersections with other cinema and cultural thinkers, as well as with some film works.

Keywords: cinema, psychology, image, Deleuze, Benjamin.

\section{Image, cinéma et psychologie : approches entre art et science}

Résumé : Image, cinéma et psychologie - cet article tisse un dialogue entre ces trois sujets vastes et complexes pour développer des approches théorico-conceptuelles entre art et science. Prenant comme référence l'art cinématographique, de certaines de ses ressources techniques et des concepts développés par ce langage, l'article cherche à établir un pont entre le domaine de l'esthétique et des réflexions sur le processus de subjectivation. L'article s'appuie sur la philosophie de l'image et du temps de Deleuze et la conception de Benjamin selon laquelle l'image est une substance qui façonne la pensée et le temps est un instant éternel qui ne cesse de s'actualiser. Les deux théories sont abordées de manière dialogique pour établir des liens avec d'autres penseurs du cinéma et de la culture, ainsi qu'avec certaines œuvres cinématographiques.

Mots-clés : cinéma, psychologie, image, Deleuze, Benjamin.

\section{Imagen, cine y psicología: aproximaciones entre arte y ciencia}

Resumen: Imagen, cine y psicología: este artículo teje un diálogo entre estos tres amplios y complejos temas para desarrollar aproximaciones teórico-conceptuales entre el arte y la ciencia. Tomando como referencia el arte cinematográfico, de algunos de sus recursos técnicos y los conceptos desarrollados por este lenguaje, el artículo busca tender un puente entre el campo de la estética y las reflexiones sobre el proceso de subjetivación. Este se basa en la filosofía de la imagen y el tiempo de Deleuze y en la comprensión de Benjamin de la imagen como una sustancia que da forma al pensamiento y del tiempo como un instante eterno que nunca deja de actualizarse. Ambas teorías se desalojan de forma dialógica para establecer intersecciones con otros pensadores del cine y la cultura, así como con algunas obras cinematográficas.

Palabras clave: cine, psicología, imagen, Deleuze, Benjamin.

\section{Referências}

Adorno, T., \& Horkheimer, M. (2014). O iluminismo como mistificação das massas. In T. Adorno, Indústria cultural e sociedade (pp. 7-74). São Paulo, SP: Paz e Terra.

Aumont, J. (2003). Dicionário teórico e crítico de cinema. Campinas, SP: Papirus.

Aumont, J. (2012). A imagem. Campinas, SP: Papirus.

Benjamin, W. (2008). Magia e técnica, arte e política: ensaios sobre literatura e história da cultura. São Paulo, SP: Brasiliense.

Benjamin, W. (2009). Passagens. Belo Horizonte, MG: UFMG.

Benjamin, W. (2012a). Imagens do pensamento. In W. Benjamin, Rua de mão única (pp. 147-285). São Paulo, SP: Brasiliense.

Benjamin, W. (2012b). Infância em Berlin por Volta de 1900. In W. Benjamin, Rua de mão única (pp. 73-145). São Paulo, SP: Brasiliense.

Benjamin, W. (2012c). Rua de mão única. In W. Benjamin, Rua de mão única. (pp. 9-71). São Paulo, SP: Brasiliense.
Benjamin, W. (2016). Origem do drama trágico alemão. Belo Horizonte, MG: Autêntica.

Carrière, J.-C. (2015). A linguagem secreta do cinema. Rio de Janeiro, RJ: Nova Fronteira.

Comolli, J.-L. (2010). Introdução. In J.-L. Comolli, Cine contra espectáculo (pp. 9-17). Buenos Aires: Manantial.

Debord, G. (1997). A Sociedade do espetáculo: comentários sobre a sociedade do espetáculo. Rio de Janeiro, RJ: Contraponto.

Deleuze, G. (2013). A imagem-tempo. São Paulo, SP: Brasiliense.

Deleuze, G. (2018). Cinema I - A imagem-movimento. São Paulo, SP: Editora 34.

Eco, U. (2006). Apocalípticos e integrados. São Paulo, SP: Perspectiva.

Fellini, F. (Diretor). (1954). La Strada [DVD] Roma: PontiDe Laurentiis Cinematografica.

Fortes, M. I. A. (2015). A dor forasteira e o belo passageiro: perspectivas nietzschiana e freudiana. Psicologia USP, 26(2), 279-285. doi: 10.1590/0103-6564D20140032 
Guattari, F., \& Rolnik, S. (1996). Cartografias do desejo. Petrópolis, RJ: Vozes.

Guido, H., \& Estevinho-Guido, L. F. (2012) A poética do movimento: considerações preliminares ao cinema. In R. A. T. Silveira \& S. Schaefer, O cinema brasileiro e a filosofia (pp. 9-31). Uberlândia, MG: Edufu.

Hobsbawm, E. (1995). A era dos extremos. São Paulo, SP: Companhia das Letras.

Merleau-Ponty, M. (2018). O cinema e a nova psicologia. In I. Xavier, $A$ experiência do cinema (antologia) (pp. 7-100). São Paulo, SP: Paz e Terra.

Morin, E. (2018). A alma do cinema. In I, Xavier, A experiência do cinema (antologia) (pp. 119-143). São Paulo, SP: Paz e Terra.

Pernisa, C., Jr., \& Landim, M. (2008). O pensamento como imagem. In C. Pernisa, Jr., F. Furtado, \& N. Alvarenga, Walter Benjamin: imagens (pp. 27-44). Rio de Janeiro, RJ: Mauad X.
Rancière, J. (2005). A partilha do sensível. São Paulo, SP: Editora 34.

Rancière, J. (2012). O destino das imagens. In J. Rancière, $O$ destino das Imagens (pp. 9-41). Rio de Janeiro, RJ: Contraponto.

Sampaio, E. (2007). O argumento do criador do conhecimento em Nietzsche. Kriterion, 48(115), 89-106. doi: 10.1590/ S0100-512X2007000100006

Vertov, D. (2018). Nascimento do Cine-Olho. In I. Xavier, A experiência do cinema (antologia) (pp. 201-215). São Paulo, SP: Paz e Terra.

Wenders, W. (Diretor). (1985). TOKYO-Ga [DVD]. Berlin: Chris Sievernich Filmproduktion.

Recebido: $29 / 06 / 2020$

Revisado: 18/04/2021

Aprovado: 24/10/2021 